University for Business and Technology in Kosovo

UBT Knowledge Center

UBT International Conference

2015 UBT International Conference

Nov 7th, 9:00 AM - 5:00 PM

\title{
Determinants of transition from school to work in Albania
}

\author{
Eni Alikaj \\ University of Tirana \\ Esmerelda Shehaj \\ University of Tirana, esmeralda.alb@gmail.com
}

Follow this and additional works at: https://knowledgecenter.ubt-uni.net/conference

Part of the Business Commons

\section{Recommended Citation}

Alikaj, Eni and Shehaj, Esmerelda, "Determinants of transition from school to work in Albania" (2015). UBT International Conference. 24.

https://knowledgecenter.ubt-uni.net/conference/2015/all-events/24

This Event is brought to you for free and open access by the Publication and Journals at UBT Knowledge Center. It has been accepted for inclusion in UBT International Conference by an authorized administrator of UBT Knowledge Center. For more information, please contact knowledge.center@ubt-uni.net. 


\title{
Determinants of transition from school to work in Albania
}

\author{
Eni Alikaj ${ }^{1}$, Esmeralda Shehaj ${ }^{2}$ \\ ${ }^{1}$ Faculty of Economics, University of Tirana \\ ${ }^{2}$ University of Tirana, Faculty of Economics, Department of Economics, Rruga “Arben \\ Broci”, Nr. 1, Tirana, Albania \\ esmeralda.alb@gmail.com²
}

\begin{abstract}
The transition from school to work is a very important stage in the life of the youngsters, during which they aim at a satisfactory integration in the labour market. However, in this process they often face different barriers, such as high unemployment rates, and economic inactivity. In Albania, youth unemployment is about twice as much as that of the total unemployment rates and has shown an increasing trend during the last years. In $2014,32.5 \%$ of the youngsters were unemployed. Furthermore, the rate of those not being in employment, education, and/or training in 2014 was $34.5 \%$, of which $36 \%$ are unemployed, while the rest remain out of the labour market because they are discouraged $(23 \%)$, dealing with household chores and family responsibilities $(19.4 \%)$ or any other reason $(21.4 \%)$. From a gender perspective, male youngsters are more active than females, with an extremely high difference of about 30 percentage points between them, although the inactivity rates are almost equal.

This paper uses the Albanian Living Standards Measurement Survey 2012 to investigate the factors that affect the transition from school to work in Albania. It employs survival model estimation and uses the time span from education completion to their first job as a dependent variable and several individual, household and community/regional level independent variables. Our findings indicate that age, the level and field of education, and family background are important determinants of the transition towards the first job. Several recommendations with regards to decreasing transition times are provided in the paper.
\end{abstract}

Keywords: School to work transition, survival model, LSMS 2012, Albania.

\section{Introduction}

Youth is a very important stage of life, when the youngsters begin to fulfill their purposes, seek for economic independence and want to find their place in society. The transition between receiving the "youth" status and the labour market, often happen at the same time and this period is not the same for all youngsters. According to World Bank (2010), the school to work transition refers to the period of life when a socio-economic change happens between the age 15 and 24 years; a period when youngsters build and develop their skills.

The aim of this study is to investigate through an empirical model, the factors that have an impact on the school to work transition process in Albania, using data drawn from the Albanian Living Standards Measurement Survey 2012. To this aim the paper is organized in five sections. Section 2 deals with theoretical aspects of the transition from school to work. Section 3 gives an insight into the literature review. Section 4 offers an overview of the Albanian context with regards to school to work transition and presents the data and methodology used in the empirical model estimation. Section 5 presents the empirical results of the model on the factors affecting the school to work transition process in Albania. Section 6 concludes. 


\section{Theoretical aspects}

The definition of the school to work transition term requires a special attention, given that the definition determines interpretation. According to OECD (1996), the transition from school to work, is the period between the end of compulsory education and reaching a full-time and stable employment. International Labour Organization (2005): "The school to work transition is defined as the passage of a young person (aged 15 to 29 years) from the end of schooling to the first fixed-term or satisfactory employment. While in many contexts, a young person is often defined as a person between the ages 15 and 24 years, for study purposes the end year is extended to 29 years. This is done with the aim to capture as much information as possible, considering that some youngsters remain in education beyond the age of 24 years.

School to work transition studies the length or the velocity by which youth make the transition from leaving the formal education system into obtaining a job that lasts for more than three months. ILO (2005) has made a basic classification for school to work transition and it includes three important stages: Transited: A young person's transition is completed, if he/she is currently employed in a fixedterm and stable job. In transition: A young person who is: currently unemployed, currently employed in a temporary job, currently not-active and not in school, with the aim to go to school later. Transition not yet started: A young person, who is: still in school, currently inactive and not in school, with no aim to look for a job.

\section{Literature Review}

A large part of the literature on the research for school to work transition, focuses on the micro level. In the studies of the last decades, the interests of research have been connected mainly with the impact of education in the duration of finding the first significant job. Other factors such as: family background, the level of education of the parents and the employment status, the role of gender etc, have been taken into consideration to explain the probability of the youngsters to find their first job. Lasibille et.al (2001), use data from the National Institute of Statistics in Spain to explain the probability of Spanish youngsters to find the first job in 6 months time or between 6 and 18 months, compared to the probability of finding the first job in a period of time more than 18 months. They use a multinomial logit model. Empirical results show that human capital, has a strong impact on the duration of first unemployment. Also those people who have a higher education, have a shorter period of first unemployment. Females have a lower chance to find their first job in less than 18 months compared to males. Family background has no effect.

Nguyen and Taylor (2005), study the transition from school to work in USA, using data from National Education Study (1988-2000). The estimation is done using a proportional hazards model, to identify the factors that have an impact on the duration of finding the first job, after higher education is completed. The length of time until finding the first job, depends on educational achievements and the type of school attended: attending a professional program reduces the time needed to find the first job. Family background results unimportant.

Chuang (1997) makes an empirical study using data from Taiwan about the process of searching for the first job, based on a structural form of evaluation approach. The average length of time in searching for a job, is longer for those people who have a bachelor degree, compared to all other college graduates, for both genders. Male graduates tend to have a shorter length of time in searching for a job, opposite to female graduates. Less than one third of graduates, had a job one month after leaving the formal education system and more than $90 \%$ had a job within a year from graduation.

Betss et.al (2000), study the time needed for Canadian graduates to start a full time job that lasts 6 months or more. The authors use data for three years $(1982,1986,1990)$, drawn from the National Graduate Survey. The analysis is done with Cox proportional hazards model. Phd graduates, have a shorter duration in finding the first job compared to other graduates and those who are married have faster transitions compared to the not married. Female graduates have lower hazard ratios than males, but the effect is statistically significant only for 1986 group.

Biggeri et. al (2001), using data from a survey about the chances of employment for Italian graduates in 1992 and survival analysis, find that the status of employment of the parents and the level of education when receiving the diploma are significant. Also, the information linked with academic 
skills (final marks), has a positive effect on the probability of getting the first job after graduation. Graduates who have worked before have more chances to find a job sooner.

\section{Youth labour market in Albania}

One of the most important indicators for school to work transition, is unemployment rate, which is also used as a measure for the difficulties that youngsters face in their search for a job. The unemployment rate has always been increasing for the cohorts 15-24 and 15-29 years. The unemployment rate for the youngsters (15-29 years), reached its highest level in 2014 (32.5\%). From a comparative perspective, youth unemployment rate is quite high, almost twice the total unemployment rate.

Table 1. Unemployment rate in (\%) in Albania, (2007-2014)

\begin{tabular}{|l|c|c|c|c|c|c|c|c|}
\hline & $\mathbf{2 0 0 7}$ & $\mathbf{2 0 0 8}$ & $\mathbf{2 0 0 9}$ & $\mathbf{2 0 1 0}$ & $\mathbf{2 0 1 1}$ & $\mathbf{2 0 1 2}$ & $\mathbf{2 0 1 3}$ & $\mathbf{2 0 1 4}$ \\
\hline $\begin{array}{l}\text { Unemployment } \\
\text { rate (\%) }\end{array}$ & 13.4 & 13.1 & 13.8 & 14.0 & 14.0 & 13.4 & 15.8 & 17.5 \\
\hline $\begin{array}{l}\text { Youth unemp. } \\
(15-24)(\%)\end{array}$ & 22.3 & 26.5 & 25.2 & 25.8 & 27.0 & 28.3 & 28.7 & - \\
\hline $\begin{array}{l}\text { Youth unemp. } \\
(15-29)(\%)\end{array}$ & 19.8 & 24.7 & 21.9 & 22.5 & 21.9 & 26 & 27.2 & 32.5 \\
\hline
\end{tabular}

Source: Labour Force Survey (2008-2014); World Bank (2015)

The main indicator, directly linked with school to work transition, is the rate of the youngsters who are not in education, employment or training (NEET). In 2014, the youngsters between the ages 15 29 years, who are not in employment nor attending school or any professional program, comprise $34.5 \%$ of the youngsters in total. Among these, $36 \%$ are unemployed. The other part is outside the labour market, because: they are discouraged $(23 \%)$, dealing with household chores and family responsibilities $(19.4 \%)$ or for other reasons $(21.4 \%)$.

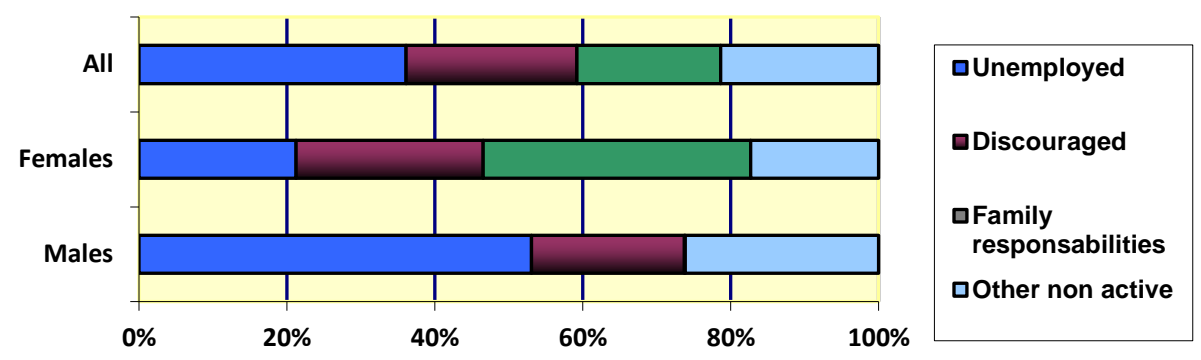

Source: Instat (2015)

Figure 1. NEET rate (15-29 years)

From a gender perspective, males are more active than females because $52.9 \%$ of them are searching for a job and are ready to work, compared to $21.2 \%$ of females. A higher percentage of females deals with family responsibilities $(36.2 \%$ compared to $0.5 \%$ for males), and are discouraged (25.3\% compared to $20.6 \%$ ). The inactivity scale is almost the same for both genders.

\subsection{Data and methodology}

This study uses data drawn from Albanian LSMS 2012, which is conducted by the Institute of Statistics and contains detailed data on a individual and family level, for many social and economic areas: education, labour market, income/consumption etc. It includes a sample of 6671 families and is representative at the regional, prefecture and the national level. The dependant variable in the model is the duration of first unemployment, while the independent variables are: age, gender, the level of education, the area where the person lives and profession. 
For the empirical estimation, is used the survival analysis model, which is the appropriate econometric methodology to explain the duration of first unemployment. The model analysis begins by considering the variable $\boldsymbol{T}$ which in our case, measures the duration of first unemployment, the period between end of studies and entering the labour market for the first time. The main function is the hazard rate that is expressed as:

$$
\lambda(\mathrm{t})=\lim _{\Delta t \rightarrow 0} \frac{\operatorname{Prob}\left(t \leq T \leq t+\frac{\Delta t}{T} \geq t\right)}{\Delta t}=\frac{f(t)}{1-F(t)}
$$

$\lambda(t)$ gives the rate of failure per time unit. The numerator of this expression, is the conditional probability that the event occurs in the interval $[\mathrm{t}, \mathrm{t}+\mathrm{dt}$ ), taking in consideration that the event has not occurred before. The denominator is the width of the interval. When the limit of the interval width goes to zero, this gives an instantaneous rate of the event occurrence. The hazard rate is an unobserved variable, but it controls the occurrence and the duration of event, that is why it is the main dependant variable in the survival data analysis.

Cox proportional hazards model (Cox, 1972), emphasizes that the hazard rate, is given as:

$$
h(t / X)=h_{0}(t) \exp (X \beta)
$$

$\mathbf{h}_{0}(\mathbf{t})$ is the baseline hazard which includes $\mathbf{t}$ but not the vector $\mathbf{X}$ (the vector of explanatory variables), is left unspecified and must be positive; while the second component includes the vector but not $\mathbf{t}$. The second part is given as a linear function of a group of k- explanatory variables, in an exponential form:

$$
\begin{gathered}
h_{i}(t)=\lambda_{0}(t) * e^{\beta_{1} X_{i 1}+\ldots .+\beta_{k} X_{i k}} \\
\log h_{i}(t)=\log \lambda_{0}(t)+\beta_{1} X_{i 1}+\beta_{2} X_{i 2}+\ldots .+\beta_{k} X_{i k}
\end{gathered}
$$

Equations (3) and (4) indicate that it is possible to consider each of the forms given. In this model, the equations lead to two main assumptions. Firstly, they specify a multiplicative relation between the hazard function and the log-linear form function of the explanatory variables. This is the proportionality assumption. Secondly, there is a log-linear relation between the independent variable and the baseline hazard. The empirical estimation and results are carried out using the STATA 12 software.

\section{Empirical results}

The interpretation of results is given as the hazard rate of the variables involved in the analysis. A hazard rate higher than 1 means a "high failure rate", which in the context of the school to work transition means a shorter duration of first unemployment. Whereas a hazard rate lower than 1 means a longer period of first unemployment. The proportionality assumption is violated and the estimation is done with a parametric model. The results of the test show that the null hypothesis (the risk is proportional) is rejected, because prob $>\mathrm{chi}^{2}=0.000$. So the estimation is done with a parametric model. Akaike Information Criteria, is used to select the appropriate parametric model and the one with the lowest AIC is the most adquate. In this case the parametric model used is Weibull. The results of the empirical estimation are presented in the table below.

Table 2. Output of the Weibull regression

\begin{tabular}{|l|c|c|c|c|c|}
\hline No of subjects $=1509$ & \multicolumn{5}{c|}{ No of observations $=1509$} \\
\hline No of failures $=1509$ & $\mathrm{LnL}=-1532.6814$ & \multicolumn{3}{c|}{ Prob $>$ chi2 $=0.0000$} \\
\hline \multicolumn{1}{|c|}{$\mathrm{t}$} & Haz.Ratio & Coef & Std. Err. & $\mathrm{z}$ & $\mathrm{P}>|\mathrm{z}|$ \\
\hline age & 0.827 & -0.190 & 0.006 & -25.610 & 0.000 \\
\hline gender01 & 1.111 & 0.105 & 0.067 & 1.750 & 0.079 \\
\hline urban01 & 1.037 & 0.037 & 0.069 & 0.550 & 0.584 \\
\hline educ02 & 1.490 & 0.399 & 0.211 & 2.810 & 0.005 \\
\hline educ03 & 4.061 & 1.401 & 0.437 & 13.020 & 0.000 \\
\hline
\end{tabular}


International Conference on Management, Business and Economics, Nov 2015

\begin{tabular}{|l|l|l|l|l|l|} 
managers & 1.170 & 0.157 & 0.309 & 0.590 & 0.590 \\
\hline professionals & 1.591 & 0.464 & 0.225 & 0.001 & 0.001 \\
\hline technicians & 1.381 & 0.323 & 0.214 & 2.080 & 0.037 \\
\hline clerical & 1.263 & 0.233 & 0.238 & 1.240 & 0.216 \\
\hline service & 1.278 & 0.245 & 0.138 & 2.280 & 0.223 \\
\hline skilled_agri & 1.636 & 0.492 & 0.163 & 4.950 & 0.000 \\
\hline craft & 1.150 & 0.140 & 0.123 & 1.310 & 0.190 \\
\hline operators & 1.145 & 0.135 & 0.149 & 1.040 & 0.298 \\
\hline cons & 3.055 & 1.117 & 0.652 & 5.230 & 0.000 \\
\hline
\end{tabular}

The statistically significant variables are age, the level of education, and the profession. Age has a hazard rate lower than 1 while the other variables have a hazard rate higher than 1 . The age coefficient is -0.1904 . This means that if age increases by one year, failure time, i.e time to finding a job or ending the period of unemployment decreases by $17.4 \%$. The coefficient of the binary variable that indicates if a person has a secondary education is 0.0366 . These people have a failure time $49 \%$ higher than those with primary education, (the reference category). While people with tertiary education have a failure time $6.07 \%$ higher than the reference category.

The binary variable professionals has a coefficient of 0.464 . Individuals who work as professionals have a failure time $59 \%$ higher than individuals who work in elementary occupation (the reference category). Technicians and associate professionals and those who have a profession related to service and sales sector, have the respectively coefficients of 0.322 and 0.233 . This means that technicians have a failure time $38 \%$ higher than those who work in elementary occupation, while those who are in the sales and service sector have a failure time $27.8 \%$ higher. Finally the variable skilled_agri, has a coefficient of 0.492 . This means that those in the skilled agricultural, forestry and fishery work force have a failure time $63.6 \%$ higher than those in elementary occupations.

\section{Conclusions and recommendations}

Our results indicate that individual factors, such as age, the level of education and the type of profession, play an important role in the school to work transition process. The level of education has a positive impact in the first period of unemployment. Whereas age has a negative impact, as expected. The duration of first unemployment is also affected by the type of profession selected. People who are professionals, technicians or work in the higher end of the agriculture sector have a shorter duration of first unemployment.

Depsite the results, the process of school to work transition for the Albanian youngsters is complex and should be seen in the light of many aspects. The high rates of unemployment and the difficulties of the youngsters to integrate in the labour market are indicators of a difficult transition. More attention is needed for developing and carrying out policies that target this phase of life of the youngsters, which is expected to be the most insecure one. More detailed and comprehensive studies should be made in the future in order to feed the policymaking process.

\section{References}

1. Alissa, S.: School to work transition of young people in Syria. ILO, Employment Policy Paper (2007)

2. Betts, J., Ferrall, C., Finnie, R.: The transition to work for Canadian university graduates: time to first job, 1982-1990. Statistics Canada, Analytical Studies Branch - Research Paper Series No. 141 (2000)

3. Biggeri, L., Bini, M., Grilli, L., The transition from university to work: a multilevel approach to the analysis of time to obtain the first job. Journal of the Royal Statistical Society (Series A) 164, (2001) 293-305

4. Chuang, H.-L: Estimating a structural search model for College graduates in Taiwan. Asian Economic Journal 11, (1997) 95-110 
5. Corrales, H., Rodriguez, B.: Transition from education to first significant job in Spain: the influence of educational attainment. The 58th International Atlantic Economic Conference. Chicago, Illinois (2004)

6. Cox, D.R.: Regression models and life-tables, Journal of the Royal Statistical Society (Series B) 34, (1972) 187-220

7. Institute of Statistics (2015), "Labour Market, 2014”, URL: http://www.instat.gov.al/media/291851/tregu_i_pun_s_2014.pdf accessed: 5.10.2015

8. Lassibille, G., Navarro, L., Aguilar, I., Sánchez, C.: Youth transition from school to work in Spain. Economics of Education Review 20, (2001) 139-149

9. Matsumoto, M., Elder, S.: Characterizing the school to work transitions of young men and women. ILO, Employment Working Paper, No.51, pg. 4 (2010)

10. Nguyen, A.N., Taylor, J.: From school to first job: a longitudinal analysis. Lancaster University Management School, Working Paper No. 15 (2005)

11. Velasco, M.S.: The transition from higher education to employment in Europe: The analysis of time to obtain the first job. Higher Education, (2007) 333-360 